
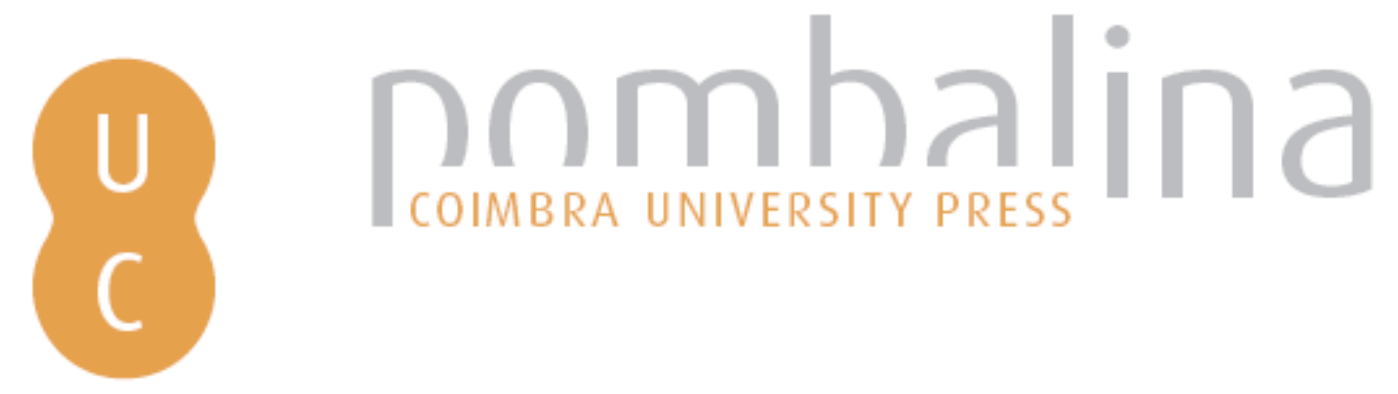

\title{
El romance odiseico de Las señas del esposo: el viaje plurisecular de una balada medieval por la geografía panhispánica
}
Autor(es):
Martín Durán, Andrés Manuel
Publicado por: Imprensa da Universidade de Coimbra
URL
persistente:
URI:http://hdl.handle.net/10316.2/44006
DOI:
DOI:https://doi.org/10.14195/978-989-26-1550-9_4
Accessed : $\quad$ 26-Apr-2023 05:30:37

A navegação consulta e descarregamento dos títulos inseridos nas Bibliotecas Digitais UC Digitalis, UC Pombalina e UC Impactum, pressupõem a aceitação plena e sem reservas dos Termos e Condições de Uso destas Bibliotecas Digitais, disponíveis em https://digitalis.uc.pt/pt-pt/termos.

Conforme exposto nos referidos Termos e Condições de Uso, o descarregamento de títulos de acesso restrito requer uma licença válida de autorização devendo o utilizador aceder ao(s) documento(s) a partir de um endereço de IP da instituição detentora da supramencionada licença.

Ao utilizador é apenas permitido o descarregamento para uso pessoal, pelo que o emprego do(s) título(s) descarregado(s) para outro fim, designadamente comercial, carece de autorização do respetivo autor ou editor da obra.

Na medida em que todas as obras da UC Digitalis se encontram protegidas pelo Código do Direito de Autor e Direitos Conexos e demais legislação aplicável, toda a cópia, parcial ou total, deste documento, nos casos em que é legalmente admitida, deverá conter ou fazer-se acompanhar por este aviso.

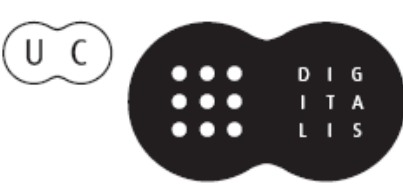




\section{Desplazamientos de la tradición clásica en las culturas hispánicas}

Paola Bellomi, Claudio Castro Filho, Elisa Sartor (eds.)

IMPRENSA DA UNIVERSIDADE DE COIMBRA 


\title{
El ROMANCE ODISEICO DE LAS SEÑAS DEL ESPOSO: EL VIAJE PLURISECULAR DE UNA BALADA MEDIEVAL POR LA GEOGRAFÍA PANHISPÁNICA \\ (The odyssey romance of Las señas del esposo: the plurisecular journey of a medieval ballad by pan-Hispanic geography)
}

\author{
Andrés Manuel Martín Durán \\ UNAM Canadá (Orcid: 0000-0002-0477-1991)
}

\begin{abstract}
Resumen: El romance novelesco de Las señas del esposo es el más extendido y difundido en la tradición oral moderna en la mayor parte de las subtradiciones que conforman el romancero panhispánico. Su fábula, de antecedentes odiseicos, remite a uno de los temas comunes al folclore universal: el de la fidelidad de la mujer puesta a prueba por el marido al volver de una larga ausencia. El artículo viaja a través de la geografía romancística panhispánica, con ejemplos de cada una de las subtradiciones, analizando las diferentes variantes de discurso, de intriga y de fábula, así como las razones por las que, con palabras de Menéndez Pidal, Las señas del esposo se ha convertido en "el primer romance de la tradición oral moderna”. Así mismo, se compara el romance panhispánico con otras ramas de la balada europea en las que existen canciones más o menos afines, especialmente con la francesa y con la italiana, con las que el romance comparte sus raíces medievales primigenias.

Palabras clave: romancero, balada, literatura oral, Las señas del esposo, La odisea, literatura filipina.
\end{abstract}

Aвstract: Las señas del esposo is the most popular and disseminated romance throughout the whole Hispanic world in almost all areas of tradition, and with many hundreds of modern versions. The theme of Las señas del esposo, where a wife's faithfulness is put to the test by her husband after his return from a lenghty absence, refers to a common theme of the universal folklore, also present in The Odyssey. This work includes examples from each area of oral tradition, and analyses their different structural levels (speech, intrigue and fable), as well as the reasons why, as per the words of Menendez Pidal, Las señas del esposo has become "the first romance of modern oral tradition." At last, this article compares the pan-Hispanic romance with other branches of the European ballad where there are more or less similar songs, especially with the French and the Italian, with which the pan-Hispanic romance shares its original medieval roots.

Keywords: Romancero, European Ballad, Oral literature, Las señas del esposo, Odyssey, Philippine literature.

El tema odiseico de la fidelidad de la mujer puesta a prueba por el marido al volver de una larga ausencia, común al folclore universal, se documenta en el romancero panhispánico con diversos romances, siendo el de Las señas del esposo 
el que ha gozado de mayor fortuna, hasta el punto de haberse convertido en el más extendido y difundido en la tradición oral moderna en la mayor parte de las subtradiciones que conforman el romancero panhispánico (Catarella 1990: 342343; Díaz Roig 1979: 121-122; Bénichou 1968: 227-234; Bronzini: 1958)1 ${ }^{1}$ Esta omnipresencia a lo largo de toda la geografía panhispánica llevó a Menéndez Pidal (1953: I, 194) a calificarlo como "el primer romance de la tradición oral moderna".

El romance de Las señas del esposo — cuya intriga en la mayor parte del corpus se desarrolla en una sola escena con una estructura dialogada de principio a fin, a veces precedida por unos versos de introducción en los que se sitúa la escena y los personajes a modo de acotación teatral - parte de una conversación en la que una mujer pregunta a un caballero (que a la postre resultará ser su marido) si tiene noticias de su esposo, quien habría marchado a la guerra largo tiempo ha. El caballero pide las señas del marido y ella se las da. Él le contesta que el hombre que responde a tales señas ha muerto y le ofrece ser su nuevo esposo. En la gran mayoría de las versiones ella rechaza el ofrecimiento, declarando su intención de ingresar en un convento hasta el fin de sus días (y determinando acto seguido el futuro de su prole), por lo que pasa con éxito la prueba de honestidad y fidelidad a la que ha sido sometida por su subrepticio cónyuge, demostrando su amor hacia el esposo incluso después del fallecimiento de este. El romance concluye en buena parte del corpus con el marido dándose a conocer.

Una de las características singulares del romance es el variado y dispar abanico de rimas de las versiones documentadas en el corpus panhispánico -é, $\dot{e}-a, \hat{a}-a, \hat{\imath}, \hat{i}-0$, más las híbridas en las que alternan los versos en $\tilde{e}+\hat{a}, \hat{e}+\hat{i}-o, \dot{e}$ $+\hat{a}-o, \hat{a}-a+i, \hat{e}-a+\hat{e}$, entre otras diversas poliasonancias- que comúnmente se corresponden con las diversas subtradiciones geográficas, si bien la rima predominante en el conjunto del corpus es en é.

Reproduzco como ejemplo del tema de Las señas del esposo una versión inédita que recogí en República Dominicana a principios del siglo XXI, en cuyo final se da a conocer el marido, no sin cierto gracejo:

- Señora, me voy pa Francia, señora, ¿qué manda usted?

2 - Señor, yo no mando nada, le agradezco su merced.

Si me ves a mi marido memorias me le da usted.

4 - No conozco su marido ni lo puedo conocer.

Deme las señas de él.

6 - Mi marido es alto y rubio, tiene tipo aragonés, y en la copa del sombrero tiene un letrero francés;

\footnotetext{
${ }^{1}$ Véase además el Proyecto sobre el Romancero pan-bispánico, Washington University, dirigido por Suzanne H. Petersen [https://depts.washington.edu/hisprom/optional/balladaction. php?igrh=0113].
} 
8 cuando yo era chiquitica en la escuela lo bordé.

- Por las señas que me ha dado su marido muerto es.

10 - Si mi marido se ha muerto, a monja me meteré;

porque yo tengo tres hijas, todas las repartiré:

12 y una para doña Ana, otra para doña Inés,

la más chiquita y bonita con usted la casaré.

14 - ¡Cómo me voy yo a casar con hija que yo engendré!

Existe un número de versiones en las que la comunidad de transmisores y recreadores de la tradición oral han introducido una sugerente variante por la que se podría apreciar en el análisis del discurso, como lectura e interpretación alternativa, cierta disimulada complicidad en la pareja, lo cual revelaría que la mujer habría reconocido al marido desde el primer momento y le estaría siguiendo irónicamente el juego. Sirva de ejemplo esta versión cubana que recogí en 2004 (Martín Durán 2016: 204):

- Mañana me voy pa Francia, qué es lo que vas mandar.

2 - Mandaremos una carta para mi esposo Manuel.

- Deme su señal señora, pa poderlo conocer.

4 - Mi marido es alto y rubio, que se me parece a usted.

- Según la señal que me ha dado su esposo muerto es.

6 A él yo lo vi matar en la puerta de un café.

- Siete años lo he esperado, siete más lo esperaré,

8 y si a los siete no ha llegado, con usted me casaré.

Estas tres hijas que tengo son las que me dan quehacer:

10 una pa su tía Juana y otra pa su tía Inés;

con la más chiquita me quedaré

12 pa que me lave y me planche y me haga lo que hacer.

Y si no lo sabe hacer a palos la mataré. ${ }^{3}$

Así parecen indicarlo los versos 4 (-Mi marido es alto y rubio / que se me parece a usted.) y 8 (y si a los siete no ha llegado, / con usted me casaré), en los que se podría intuir el reconocimiento del esposo, por lo que el diálogo entre los cónyuges se entendería como un juego irónico repleto de picardía y complicidad ${ }^{4}$.

${ }^{2}$ Versión de Peralta (provincia de Azua) cantada por Lorenza Rodríguez Mateo, una anciana centenaria. Recogida en San José de Ocoa (provincia de Ocoa) por Andrés Manuel Martín Durán el 8 de diciembre de 2003. El tercero de los versos está "cojo" de uno de sus dos hemistiquios como consecuencia probablemente de una deturpación en su proceso de transmisión oral.

${ }^{3}$ Versión de Los Names (municipio de Guamá, provincia de Santiago de Cuba) cantada por Nancy Rodríguez Bustamante, de 55 años de edad. Recogida en Río Grande (municipio de Guamá) por María Victoria Labrada Peña y Andrés Manuel Martín Durán el 9 de diciembre de 2004.

${ }^{4}$ Mercedes Díaz Roig 1979: 128 lo interpreta de forma distinta: para ella se trataría de una variante emanada de la estructura del romance para poner al público en antecedentes de la intriga. 
En otro grupo de versiones del tema - cuya geografía se sitúa en el noroeste de la península y Portugal - encontramos una destacada variante de intriga: el subrepticio marido, tras comunicar a la esposa su espurio fallecimiento, lleva la prueba de honestidad y fidelidad a límites extremos al preguntar a la mujer qué le daría si le trajese a su cónyuge con vida; no contentándose con las sucesivas ofrendas que ella le propone, le solicita finalmente, de forma tácita o expresa, que le entregue su cuerpo. Como ejemplo reproduzco esta versión portuguesa (Ferré 2001: 80), con rima en á-a + í, que incluye uno de los versos característicos de este subtipo, "no tengo yo más que dar / ni usted más que pedir", de exquisita sutileza:

Estando Quelaralinda no seu jardim assentada,

2 com pente d'ouro na mão seu cabelo penteava.

Deitando os olhos ao mar viu vir uma grande armada,

4 capitão que nela vinha a trazia bem guiada.

- Diz-me cá, ó capitão, diz-me cá por tua alma,

6 marido que Deus me deu, aí vem na tua armada?

- Não o vi nem o conheço, nem sei que sinais levava.

8 - Levava cavalo branco con sua sela amarela, na punta da sua espada levava bandeira de guerra.

10 Ai de mim, triste viúva! Ai de mim o que farei?!

Com água dos meus olhos, filhinhas, vos lavarei,

12 com a trança dos meus cabelos, filhinhas, vos cobrirei.

- Quanto dareis vós, senhora, quem vo-lo trouxera aqui?

14 - Dava rasas de dinheiro quantas quisésseis medir.

- Não quero o vosso dinheiro que me não compete a mim,

16 quanto dareis vós, senhora, quem vo-lo trouxera aqui?

- Três moinhos que eu tenho, todos três moem marfim.

18 - Não quero os vossos moinhos que me não compete a mim, quanto dareis vós, senhora, quem vo-lo trouxera aqui?

20 - Três filhas que eu tenho, todas três eram para ti,

uma para te calçar, outra para te vestir,

22 a mais formosa de todas, para contigo dormir.

- Não quero as vossas filhas que me não compete a mim,

24 quanto dareis vós, senhora, quem vo-lo trouxera aquí?

- Não tenho mais que te dar, nem tu mais que me pedir.

26 - 'Inda tendes mais que me dar e eu mais que vos pedir, esse corpinho bem feito, para com ele dormir.

28 - Cavaleiro que tal diz deve ser arrastado, ao longo do meu jardim, aos rabos dos meus cavalos.

30 Levantai-vos, meus criados, vinde-lhe fazer assim!

- Qué e do anel das sete pedras, que eu contigo reparti? 
32 Mostra-me a tua ametade que eu a minha tenho-a aqui. ${ }^{5}$

Existe así mismo un grupo minoritario de versiones en el corpus panhispánico de Las señas del esposo, aunque especialmente significativo en la subtradición americana, en los que la esposa reacciona al anuncio de la muerte del marido con variantes bien distintas: tomando nuevos amores, propiciándolos, o mostrando su alegría por quedar viuda joven y bonita. El tema sufre entonces una transformación radical: deja de ser el alegato de fidelidad ejemplar (que el matrimonio conllevaría necesariamente para "las esposas modélicas") confirmado con el paso victorioso de la prueba por parte de la mujer, para convertirse en el tópico misógino tan extendido de la liviandad y la volubilidad intrínsecamente asociadas al género femenino, con importantes matices según cada versión. Como ejemplos de este tipo, frecuente en el continente americano, voy a tomar una versión dominicana y otra cubana. La primera procede de la provincia quisqueyana de Duarte y en ella la esposa muestra su alegría por haber quedado viuda con juventud, lozanía y belleza:

- Yo soy la recién casada que no dejo de llorar,

2 me abandonó mi marido por amar la libertad.

Venga acá, mi buen soldado, ¿No ha visto usted a mi marido?

4 - No señora, no lo he visto, deme usted las señas de él.

Él es alto, blanco y rubio, tiene tipo de francés,

6 y en el puño de la espada tiene el nombre de Isabel.

- Sí señora, yo le he visto, hace un año que murió,

8 en la plaza Cartagena un español lo mató.

- Ya se murió mi marido, tan solita yo quedé,

10 y me miro en el espejo: iqué joven viuda quedé!

Yo me voy para la plaza, voy a comprar mis verduras,

12 para que la gente diga: iqué joven quedó la viuda!...

Para que los hombres digan: ¡A mí me gusta la viuda! ${ }^{6}$

Este tipo de variante, documentada sobre todo en Hispanoamérica, podría interpretarse como una respuesta funcional discordante recreada y transmitida por una parte de la comunidad — seguramente debido a la importancia de la voz femenina en el romancero novelesco de tradición oral, género femenino por excelencia (Catarella 1990) — que se rebelaría contra el tópico establecido para la

${ }^{5}$ Versión de Armamar (Viseu, Beira Alta) recitada por una niña (sin más datos del informante) en 1907 (sin datos del colector). En esta versión falta el segmento narrativo en que se anuncia el fallecimiento del esposo, que correspondería a los puntos suspensivos que denotan una laguna de memoria de la informante.

${ }^{6}$ Versión de San Francisco de Macorís (provincia de Duarte, República Dominicana) cantada por Tomasa Pérez, sin datos de edad. Recogida en San Francisco de Macorís por Edna Garrido de Boggs en agosto de 1945 (Garrido de Boggs 1946: 46-47). 
mujer que enviuda, sugiriéndole unos planes de futuro más alegres y atractivos. Sería una subversión del código moral patriarcal que parte de las mujeres reivindicaría (al menos en el ámbito privado y doméstico - habitualmente privativo femenino- donde solían cantarse los romances) o con la que fantasearía acorde con una de las funciones del folclore (Bascom 1965) - como solución alternativa al luto de por vida o al monacato. Por más que las comunidades sefardíes no sean representativas de las sociedades tradicionales campesinas de otros ámbitos panhispánicos, creo que viene al caso recordar las palabras de Oro Anahory-Librowicz (1989: 183):

Los romances se cantaban entre mujeres, entre las cuatro paredes de una casa, mientras se hacían los quehaceres domésticos o se arrullaba a una criatura, mientras se columpiaban las doncellas en los patios de la judería soñando con el varón ideal. Así que después de todo, ¿por qué no dar rienda suelta a su imaginación precisamente cuando el código ético del grupo a que una pertenece es riguroso y no permite la expresión de la sensualidad más que en el relato de lo ficticio, en el mundo de lo soñado que nada tiene que ver con la realidad?

El segundo de los ejemplos, que difiere bastante del anterior, es una versión cubana (Martín Durán 2016: 202) que plantea como futuro para la viuda unas nuevas nupcias:

- Mañana me voy pa Francia, qué es lo que queréis mandar.

2 - Mandaremos una carta para el conde de San Miguel.

- Deme la señal señora, que lo quiero conocer.

4 - Mi marido es alto y rubio, viste y calza a lo caché.

- Por la señal que me ha dado, su marido muerto es.

6 - Allá en Francia lo mataron en la esquina de un café.

- Siete años lo he esperado y siete más lo esperaré,

8 si a los ocho no regresa, otra vez me casaré. ${ }^{7}$

En este segundo ejemplo, y a diferencia del primero - en cuyo final se recrea el tópico de la viuda alegre que alaba su hermosura-, no hay jactancia alguna, sino la escueta aceptación por parte de la viuda de unas nuevas nupcias, con la variante de los largos años de luto que matizan ese "sí". Estos oscilarían, y no por casualidad, entre siete y catorce - dos veces siete- para aceptar casarse en el año ocho, con el simbolismo de cambio de estado que en la literatura tradicional se asocia a dichos números (Devoto 1959) y que podría interpretarse como la obligada y necesaria espera que la comunidad impondría para que una

${ }^{7}$ Versión de Chivirico (municipio de Guamá, provincia de Santiago de Cuba) cantada por Silvia Aguilera Rivera, de 45 años, y María Victoria Labrada Peña, de 43. Recogida en Chivirico por Andrés Manuel Martín Durán el 6 de diciembre de 2004. 
larga ausencia fuera aceptada como defunción. Si bien la esposa no pasaría en sentido estricto la prueba al no mostrar la firmeza suficiente para sostener el celibato de la viudedad de por vida, probablemente para muchos miembros de las comunidades tradicionales quince años serían suficientes para cambiar de estado (como parece sugerir el simbolismo de los guarismos de la espera: siete, catorce y ocho años), por lo que la fidelidad de la esposa no quedaría así en entredicho.

Entre los diversos análisis estructurales del tema de Las señas del esposo que los estudiosos han propuesto, creo que el de Catarella (1990) y el de Díaz Roig (1979), en el que me detendré a continuación, son especialmente interesantes. Mercedes Díaz Roig propuso un análisis estructural partiendo de la distinción que Giuseppe di Stefano (1972: 277-296 y 1973: 372-376) establecía entre romances "alfa" y romances "omega", así como del papel de los antecedentes para la comprensión de los relatos (con las consideraciones al respecto de Cesare Acutis [1974]), para después aplicar el concepto de "función" que Propp definió en su Morfología del cuento (1971):

Su estructura [la del romance de Las señas del esposo] es desde luego alfa [sucesión de acontecimientos presentados cronológicamente], pero varía respecto a las estructuras alfa típicas ya que se oculta al público un antecedente de primordial importancia (el marido disfrazado). La sorpresa final modifica lo ya contado. Los distintos elementos adquieren un sentido diferente. $Y$ aquí voy a referirme, aunque brevemente a Propp (Morphologie du conte), quien dice que las funciones son las invariantes del relato folklórico [...]. La sorpresa final modifica en el romance varias de estas funciones; así la solicitud de señas, la participación de la muerte y la solicitud de amores se convierten en engaño a la heroína y prueba de su fidelidad; el dolor de la noticia y el rechazo de la proposición, además de su función como signos de honestidad de la mujer, representan el paso victorioso de la prueba. El público, ante el final sorpresivo, tiene que reorganizar correctamente los datos que ya tenía. Siente una especie de suspenso retrospectivo al darse cuenta del peligro que corría la mujer ante las trampas del marido; también aprecia la sutileza de estas (anuncio de la muerte y de la infidelidad), que pueden propiciar que por celos retrospectivos y/o desamparo la mujer acepte las proposiciones, lo cual hubiera traído un castigo ejemplar (quizás la muerte a manos del marido). El público siente que en vez del desarrollo de una historia triste [...] ha presenciado un juego peligroso que podía haber desembocado en una tragedia. Esta es pues una estructura muy particular y que sólo poseen unos pocos romances (por ejemplo La hermana cautiva, Bernal Francés y El caballero burlado), una variante, creo que importante, de la estructura alfa. (Díaz Roig 1979:121 y ss.)

E1 romance de Las señas del esposo no se documenta en ninguno de los Cancioneros y Silvas quinientistas. La versión más antigua conocida del romance en el ámbito panhispánico se incluye en el último de los pliegos sueltos de la tradición 
oral de los Siglos de Oro (Menéndez Pidal 1953: 193-194), el publicado por Juan de Ribera en 1605, que daría fin a la fecunda fortuna editorial de los pliegos romancísticos del siglo XVI:

- Caballero de lejas tierras, llegaos acá y paréis,

2 hinquedes la lanza en tierra, vuestro caballo arrendéis, Preguntaros he por nuevas, si mi esposo conocéis.

4 - Vuestro marido, señora, decid ¿̇de qué señas es? - Mi marido es mozo y blanco, gentil hombre y bien cortés,

6 muy gran jugador de tablas y también del ajedrez.

En el pomo de su espada armas trae de un marqués,

8 y un ropón de brocado, y de carmesí al envés, cabe el fierro de la lanza, trae un pendón portugués,

10 que ganó en unas justas a un valiente francés. - Por esas señas, señora, tu marido muerto es:

12 en Valencia le mataron en casa de un ginovés; sobre el juego de las tablas lo matara un milanés.

14 Muchas damas lo lloraban, caballeros con arnés, sobre todo lo lloraba la hija del ginovés.

16 Todos dicen a una voz que su enamorada es. Si habéis de tomar amores por otro a mí no dejéis.

18 - No me lo mandéis, señor, señor, no me lo mandéis, que antes que eso hiciese, señor, monja me veréis.

20 - No os metáis monja, señora, pues que hacello no podéis, que vuestro marido amado delante de vos lo tenéis. ${ }^{8}$

Si comparamos el texto del pliego suelto, que nos remontaría a la tradición oral de fines del siglo XVI y comienzos del XVII, con los textos anteriormente reproducidos (y también por extensión con la mayor parte de las versiones de la tradición oral moderna), podremos fijarnos en algunos detalles de la evolución del tema tras cuatro siglos de vida oral: en estos cuatrocientos años de transmisión y recreación oral se han pulido los elementos del apero caballeresco o los relativos a la indumentaria - ya que ambos resultan anacrónicos para el siglo XXI y, por tanto, no funcionales ${ }^{2}$ - así como la mención al juego de las tablas, tan popular en el Medievo y Siglos de Oro como en desuso desde hace ya mucho tiempo en las sociedades tradicionales del ámbito hispánico; las referencias a los celos con los que el camuflado marido malmete para poner a prueba a la esposa,

${ }^{8}$ Nueve romances, el primero de Lucrecia, el segundo del Padre Santo, etc..., compuestos por Juan de Ribera y con licencia impresos, s. 1., 1605; editado por Wolf y Hofmann 1856: 88-89, de donde reproduzco la versión.

${ }_{9}$ Acerca de la importancia transcendental del criterio de funcionalidad para la pervivencia de los romances en la tradición oral moderna, véase Catalán 1997: XXVII-XXXI y Cid 2003: 162. Más adelante en este mismo trabajo me extenderé acerca de ello. 
que no forman parte de la intriga de los textos que anteriormente he utilizado como ejemplos, sí están en cambio presentes en parte de las versiones del corpus del romance en la tradición oral moderna, como en esta recogida en la provincia española de Lugo (Valenciano 1998: 313):

Estando la Isabelita sentada junto a un laurel,

2 con los pies en la frescura, viendo las aguas correr, llegó por allí un soldado y le hizo detener.

4 - Deténgase, ay, soldado, que una pregunta le haré:

si ha visto a mi marido por la guerra alguna vez.

6 - Si le he visto, no me acuerdo; deme usted las señas de él.

- Mi marido, cierto hombre, alto, rubio y cortés es,

8 y en la punta de la espada lleva la enseña del rey.

- Por las señas que usted da, ese hombre muerto es,

10 lo mataron en Valencia en casa de un genovés; ${ }^{10}$

lloraban reyes y condes, pastorcitos y marqués,

12 pero la que más lloraba, la hija del genovés.

- Siete años hay que le espero y otros siete esperaré,

14 si a los catorce no viene, monjita me meteré.

Mis chichis y mis alhajas por rosarios cambiaré,

16 y a los dos hijos varones a la patria los daré,

y a las dos hijas mujeres conmigo las llevaré.

18 - Calla, calla, Isabelita, calla, calla, Isabel,

que yo soy tu marido, tú eres mi linda mujer. ${ }^{11}$

Son los celos también, junto a la desgarradora respuesta de la esposa al oír que su marido - quien estaría vivo - la habría abandonado, los motivos más destacados en la intriga de una de las versiones más singulares del corpus, una versión sefardí recogida hace cien años en Sarajevo (Bosnia) que puede consultarse en la web de Suzanne H. Petersen:

Asentada está la reina, asentada en su verjel.

2 Agujica de oro en mano, ata bien y enfila perla.

Por ahí pasó un caballero que a su marido asemejaba.

4 - Así bivas, caballero, así Dios vos dé bonanza, ¿si viteis a mi marido al Montesico de Francia?

6 - Bien lo vide, bien lo conozco, letra en mi mano daba.

Me dijo que os buscéis otro marido, que él ya se buscó otra dama.

8 Esto que sintió la reina, grito echaba dolorioso, que los cielos borracaba y la tiera retemblaba.

${ }^{10}$ [https://depts.washington.edu/hisprom/optional/balladaction.php?igrh=0113]

${ }^{11}$ Versión de Soutelo (ayuntamiento de Ribeira de Piquín, provincia de Lugo) recitada por Elena López Fernández, de 18 años de edad. Recogida por Aníbal Otero López hacia 1928. 
10 - No lloréis vos, la mi reina, ni vos toméis dolor mucha, que yo so vuestro marido, el Montesico de Francia.

12 - Un mal ay a las mujeres que en los hombres se confían. Falsos son y mentiros, echados a la malicia. ${ }^{12}$

El tema de Las señas del esposo no solo se documenta en el romancero panhispánico - en el que está presente en todas sus subtradiciones (castellana, catalana, portuguesa, sefardí, americana) e incluso en Filipinas - sino que también es común a otras ramas de la balada europea con canciones más o menos afines. Podemos manejar un nutrido corpus de textos (véanse Menéndez y Pelayo 1900: 85-86; Vicuña Cifuentes 1912: 57-58; Bronzini 1958: 217-219; Bonamore 1986; Kioridis 2012) en francés, italiano, catalán, portugués, alemán, griego moderno, inglés, bretón o lituano. Son especialmente interesantes para el estudio del romance la tradición oral francesa e italiana, pues varias canciones tradicionales en francés e italiano están emparentadas con el romance panhispánico.

Para Menéndez Pidal (1953: 318-320) el romance de Las señas del esposo habría sido importado desde Francia y su fuente sería la balada francesa Gentilz gallans de France, documentada en el siglo $\mathrm{XV}$ en un único texto que diera a conocer en 1875 Gaston Paris:

- Gentilz gallans de France qui en la guerre allez,

2 je vous prie qu'il vous plaise mon ami saluer.

- Comment le saluroye quant point ne le cognois?

4 - Il est bon a cognoistre: il est de blanc armé.

Il porte la croix blanche, les esperons dorez,

6 et au bout de sa lance ung fer d'argent doré.

- Ne plorés plus, la belle, car il est traspassé:

8 il est mort en Bretaigne, les Bretons l'ont tué.

- J' ay veu faire sa fouce l'orée d'ung vert pré,

10 et veu chanter sa messe a quatre cordelliers. (Paris 1875: 127-128)

Pero esta hipótesis de Menéndez Pidal tiene un punto de inconsistencia, que ya advirtieran Giovanni B. Bronzini (1958) y Mercedes Díaz Roig (1979), pues en esta canción francesa solo encontramos la preocupación de la esposa por la suerte del marido y la noticia de su fallecimiento como desenlace del romance, sin que se someta a la esposa a prueba de fidelidad alguna, uno de los elementos aparentemente esenciales del romance de Las señas del esposo. No obstante, en las encuestas que llevé a cabo en Cuba en los años 2000, 2001 y 2004 pude recoger tres versiones (Martín Durán 2016: 191, 200 y 201-202) similares a la canción

${ }^{12}$ Versión de Sarajevo (Bosnia) recogida por Laura Papo en 1917 sin especificar informante, aunque bien podría ser ella misma por los datos que se incluyen en la página web, a la cual remito para más información al respecto. 
francesa del siglo XV, en las que la intriga concluye con la noticia de la muerte del marido, sin que tampoco exista prueba de fidelidad alguna ni la esposa se detenga a explicar cómo afrontará su viudez o cuál será la suerte futura de su prole:

- Buenas tardes señor soldado. - ¿Qué se le ha ofrecido a usted?

2 - ¿Usted no ha visto a mi marido en la guerra alguna vez?

- No señora, no lo he visto, deme alguna seña de él.

4 - Mi marido es blanco y rubio y de tipo aragonés, en la punta de su lanza lleva un pañuelo francés

6 que, cuando yo era niña, en la escuela lo bordé.

- Por las señas que usted ha dado su marido es muerto ya. ${ }^{13}$

- Catalina, flor de Lima, flor de todo genovés,

2 mañana me voy pa Francia, ¿qué es lo que quiere mandar?

- Mandaremos una carta para el conde don Manuel.

4 - Deme la señal señora, que la quiero conocer.

- Mi marido es alto y rubio, viste y calza a lo francés.

6 - Por la señal que me ha dado su marido muerto es.

Su marido lo mataron en la puerta de un café. ${ }^{14}$

- Mañana me voy pa Francia, qué es lo que queréis mandar.

2 - Mandaremos una carta a mi querido Manuel.

- Deme la señal señora, que lo quiero conocer.

4 - Mi marido es alto y rubio, viste y calza a lo francés.

- Por la señal que me ha dado, su marido muerto es.

6 Allá en Francia lo mataron en la puerta de un café..$^{15}$

Los cuatro informantes, procedentes de áreas cubanas de geografía folclórica distinta (véase Martín Durán 2016: 186-188), me confirmaron que la versión del romance que ellos conocían finalizaba así y que ni existían otros versos posteriores que hubieran olvidado ni continuaba de ninguna otra manera. Podría pensarse que lagunas de memoria de los informantes hubieran truncado dichas versiones, pero creo especialmente significativo para refutarlo que la versión de Santiago de Cuba fuera cantada a la par por una pareja de informantes que la habían aprendido en

${ }^{13}$ Versión de Cienfuegos cantada por María Teresa Albis Muñoz, de 60 años de edad. Recogida en Ciudad de La Habana por Andrés Manuel Martín Durán el 25 de septiembre de 2000.

${ }^{14}$ Versión de Sagua de Támano (municipio de Sagua de Támano, provincia de Holguín) cantada por Ana Milagros Durán de la Cruz, de 47 años. Recogida en Punta Gorda (municipio de Moa, provincia de Holguín) por Andrés Manuel Martín Durán el 13 de octubre de 2001.

${ }^{15}$ Versión de Santiago de Cuba cantada por Carlos Lambet Alcántara, de 75 años y natural de Jarahueca (municipio y provincia de Santiago de Cuba) y por Olga Risel Almenara, de 65 años y natural de E1 Cobre (municipio y provincia de Santiago de Cuba). Recogida en Chivirico (municipio de Guamá, provincia de Santiago de Cuba) por María Victoria Labrada Peña y Andrés Manuel Martín Durán el 3 de diciembre de 2004. 
localidades vecinas, pero diferentes, y ambos negaran taxativamente y sin ningún género de dudas que los versos tuvieran continuación o que hubieran olvidado la parte final de la canción. En estas versiones cuyo desenlace es la información escueta de la muerte del marido, la fábula del tema ya no es la de la fidelidad ejemplar (o la liviandad femenina), pues la historia del romance se limita al tópico de "las desdichas de la guerra", con la tragedia de una mujer que se entera, tras una larga espera y tras dar a un viajero las señas de su marido, de la noticia de la muerte de su cónyuge; y en ellas sorprendentemente no hay reacción alguna de la esposa, ni tampoco prueba de fidelidad, ni autoidentificación del marido. Por lo tanto, como apuntan estas versiones cubanas, al menos para ciertos transmisores y recreadores de la tradición oral en el ámbito panhispánico, esta fábula (una mujer pregunta a un soldado o viajero por su marido ausente que está en la guerra y, como respuesta, el soldado, tras pedirle las señas de su marido, le informa de la fatal noticia de su muerte) tendría un sentido completo, como la de la canción francesa del siglo XV que diera a conocer Gaston Paris. Este tipo de versiones de Las señas del esposo son las que estarían más claramente entroncadas con la balada francesa Gentilz gallans de France y podrían servir para sustentar en parte la hipótesis de Pidal, aunque esta seguiría siendo inconsistente para el resto del corpus del romance en el que, mayoritariamente, la prueba de fidelidad es uno de los elementos esenciales de su fábula.

La hipótesis pidaliana del origen francés del romance de Las señas del esposo fue matizada por Giovanni B. Bronzini (1958: 217-247) al estudiar la balada italiana de La prova, emparentada con el romance panhispánico, de la que reproduzco como ejemplo uno de los textos editados por Bronzini:

- Canta, canta, Lisetta, finché trovi da maritar.

2 - Nun vo cantar né rider, lo mio cor l'è appasionà.

El mio amor è andato a guerra, da sette anni unn'è artonnà.

4 Si sapessi la strada, l'anderei a ritrovar.

A forza di domande io la strada ritroverò.

6 Quando fu a mezza strada, un bel giovine incontrò.

- Dite, dite, bel giovane, da che parte ne venghi tu?

8 - Io ne vengo da una parte dove il sol per me va giù.

- Dite, dite, bel giovane, l'ête veduto il mio amor?

10 - Sì sì cho l'ò veduto, veduto e conosciuto.

- Alla porta di San Marco, lo portavano a seppellir. -

12 Lisetta casca in terra da la pena e dal dolor.

- Sta su, sta su, Lisetta, sono io il tuo primo amor. -

14 Lisetta s'alzò in piedi e tre baci gli donò.

Se lo prende sotto al braccio e al su padre lo riportò. ${ }^{16}$

${ }^{16}$ Versión de Città di Castello (Perugia) sin datos de informante, recogida por Giulia Torrioli, quien la incluyó en su tesis de licenciatura inédita Le tradizione popolari a Città de Castello (Perugia); reproducida por Bronzini 1958: 241. 
La balada italiana presenta gran afinidad con el romance panhispánico, pues ambos comparten un buen número de motivos: una joven cuyo enamorado lleva gran tiempo ausente por haber ido a la guerra, el encuentro con un viajero - que no es otro que su enamorado- a quien no reconoce y al que pregunta por la suerte de su amado, la prueba de fidelidad a la que este la somete anunciándole que ha muerto, el paso de la prueba por parte de la joven y la autoidentificación posterior del joven soldado. El motivo de las señas para identificar al esposo en cambio solo se encuentra en parte del corpus italiano (Nigra 1888: 314-318; Bronzini 1958: 235-236). En algunas versiones este motivo de las señas se ha elidido, como en el texto de Perugia anteriormente reproducido, o es la joven la que pide las señas de identificación para asegurarse de que el fallecido sea su enamorado, como en este texto de Ascoli (Bronzini 1958: 240):

- Il mio amore è andato in guerra, chissà quando ritornerà.

2 chissà, quando, chissà quando ritornerà.

Se io sapessi la strada lo andrei a rincontrà. -

4 Nel mentre camminavo un bel giovane mi incontrò.

- Dimmi, dimmi, quel giovane, se lo ài visto il mio primo amò.

6 - Sì sì, sì sì l'ò visto, ma non l'ò riconosciù.

- Dimmi, dimmi bel giovane, con che panni era vestì?

8 - La giubba di scolante, pantaloni imperatò.

- Dimmi, dimmi bel giovane, da chi era accompagnà?

10 - Da un frate e tre becchini che lo andavano a soterrà. -

Ninetta getta un grido, cade a terra per morì.

12 - Su su, su su Ninetta, sono io il tuo primo amò. -

Ninetta s'alza súbito e tre bacini gli darà,

14 e al son delle campane la Ninetta si sposò.

Evviva la Ninetta che à sposato, che à sposato il suo primo amò. ${ }^{17}$

También encontramos versiones en catalán, que guardan gran afinidad con las italianas del tipo anteriormente transcrito, en las cuales es la joven la que pide las señas de identificación a un peregrino encubierto, que no es otro que su marido (Milá 1882: 154-155):

${ }^{17}$ Versión de Monte Urano (provincia de Fermo [hasta 2009 provincia de Ascoli Piceno]) recitada por Renata Riccioni, de 72 años de edad. Recogida por A. M. Rocchetti en 1957, quien se la envió a Giovanni B. Bronzini. 
S'estaba linda senyora à l'ombreta d' un pi.

2 Las ombretas eran altas, que'1 sol li tocava al pit.

Ya’n passava un cavallé no'n la gosa despertí.

4 Li tira un ram de violas, al pit las hi va tirí.

Las violas n'eran frescas, la senyora's despertí.

6 - Quí es aquet cavallé que m'ha quitat el dormí?

- Non so, cavallé, senyora, soch un pobre pelegrí.

8 - ¿No 'm diría, el cavallé las novas qu' hi per allí?

- La nova que duch, senyora, se n'es mort un pelegrí.

10 - ¿No 'm diría, 'l cavallé de quin coló va vestit?

- Porta la capa d'horlanda y la valona d'or fi,

12 y á n-el cap de la valona se ni penja un rich satí.

- ¡Ay trista de mi, mes trista, que será lo meu marit!

14 ¿No' m diría ' 1 cavallé, quant hi ha d'allí aquí?

- Cen lleugas n'hi ha, senyora, y aqueixas de mal camí.

16 - Yo l'en tinch d'aná á veure mes que 'm sápiga morí.

- No hi vaji, lina senyora, que ' 1 seu marit es aquí. ${ }^{18}$

Junto a este tipo de versiones, que Milá intitula El peregrino y que están claramente emparentadas con la canción italiana precedente, convive en la tradición oral catalana otro tipo enraizado con el romance castellano de Las señas del esposo. Reproduzco como ejemplo la documentada por Milá (y que publicó junto a El peregrino, señalando así la diferencia de ambos tipos) bajo el título de La vuelta del marido (Milá 1882: 153), con afinidades con la versión sefardí anteriormente reproducida y cuyo comienzo nos remite a una atmósfera claramente odiseica:

Estava la Blancaflor sota l'ombra de la menta,

2 que brodava un camison per la filla de la reyna.

El camisón era d' or, de seda li broda ella.

4 Quant la seda li faltá brodava de sus cabellos.

De sus cabellos al or, no hi havía diferencia.

6 Gira '1s ulls envers la mar veu venir la mar lluenta, veu vení fustas y naus y galeras mes de trenta.

8 Veu vení un galion que su gran senyor le sembla.

- Galion, bon galion, Deu te do [en] la mar bonansa.

10 Si est vist y conegut el meu gran senyor en Fransa?

- Yo l'hi vist y conegut y de sa part li comanda:

12 diu que' es cerqués aimadó que 'ell aymada s' es cercada.

La filla del rey francés por esposa li han dada.

${ }^{18}$ Milá, como era habitual en las primeras recolecciones folclóricas, no aporta datos sobre informantes, origen geográfico, fecha o identidad del colector de esta versión. 
14 - Ben haja qui presa l' ha, mal haja qui li ha dada.

Una dona com som jo per altra m' haji deixada!

16 Set anys el som esperat com á dona ben casada

y altres set le esperaré com á viudeta enviudada,

18 si al cap daquests set no ve per monja' $\mathrm{m}$ seré posada.

- No 's fassi monja, Senyora, no 's fassi pas monja encara:

20 no dormiría en llit de plomas ni en cambra encortinada,

Haurá de dormí en llit de pots sense llansol ni flassada,

22 al capsal li posarán una pedra mal picada, no beurá vi de sarment, sino d' un prunell molt aspre.

24 All vós le seu marit, li va doná una abrassada.

- Perdoni lo meu marit si he faltat en cap paraula.

26 - Perdoni la meva esposa del temps que á mi m' aguardava.

- Perdoni le meu marit si n' he 'stada mal criada.

28 - Ben criada, Blancaflor, de bon pare y bona mare. ${ }^{19}$

Aunque la referencia más odiseica del corpus de Las señas del esposo creo que se esconde en el primer verso de una versión cubana que recogí en 2004 (Martín Durán 2016: 201), el cual, en un principio, me pareció carente de sentido, consecuencia de alguna deturpación que se podría haber producido en el proceso de transmisión oral:

- Catalina, flor de Lima, flor de todo es y no es,

2 mañana me voy pa Francia, qué es lo que queréis mandar.

- Mandaremos una carta para el conde don Manuel.

4 - Dame la señal señora pa poderlo conocer.

- Mi marido es alto y rubio, viste y calza a lo francés.

6 - Por las señas que me ha dado su marido muerto es.

Su marido lo mataron en la puerta de un café.

8 Cuatro años lo he esperado, cuatro más lo esperaré, si a los ocho no viniese, a monja me meteré.

10 - No se meta usted a monja, yo le haré la caridad.

- De las tres hijas que tengo, todas las regalaré:

12 una pa su tía Juana y otra pa su tía Inés.

Con la más chiquirritica, con esa me quedaré

14 para que me lave y planche y me dé de qué comer. ${ }^{20}$

${ }^{19}$ Véase la nota anterior.

${ }^{20}$ Versión de Santa Rita (municipio de Guamá, provincia de Santiago de Cuba) cantada por Esther Rosa Romero, de 77 años. Recogida en Chivirico (municipio de Guamá, provincia de Santiago de Cuba) por Andrés Manuel Martín Durán el 2 de diciembre de 2004. 
A mi pregunta acerca del significado del hemistiquio "flor de todo es y no es", la informante que me cantó el romance me hizo la siguiente aclaración, la cual nos remite directamente a La odisea:

Significa que Catalina era bonita, pero como era casada y su marido era un soldado que estaba en la guerra, era una flor para todos, pero no lo era porque ella no aceptaba ya que era casada, porque se preocupaba de saber de su esposo.

Como Penélope, su referente homérico, Catalina sería una presunta viuda con innumerables pretendientes, a quienes rechazaría sistemáticamente con la esperanza del regreso de su marido, a pesar de los fúnebres agüeros al respecto.

Volvamos a la canción italiana. Son tantas las coincidencias entre La prova y el romance de Las señas del esposo que Giovanni B. Bronzini (1958: 221-229), quien fue el primero en reparar en ello, propuso un origen común, modificando en parte la hipótesis de Pidal. Bronzini creía que las versiones catalanas y una parte de las portuguesas no podían entroncarse directamente con el texto del romance en castellano reproducido en 1605 por Juan de Ribera. Para Bronzini, los segmentos dialogados de la intriga entre mujer y soldado en los que ella le da las señas de su esposo y él la noticia de su muerte tendrían como origen la canción francesa Gentilz gallans de France; pero el motivo de "la prueba de fidelidad", común al romance panhispánico y a la balada italiana, habría de tener como origen otro texto que Bronzini no supo determinar, y que posteriormente Mercedes Díaz Roig propuso que podría derivar de la canción de gesta francesa del siglo XII La chanson des Saisnes, siendo este texto "perdido" fuente no solo del romance de Las señas del esposo sino también del de Nuño Vero:

Menéndez Pidal [1953: 253] al hablar de los posibles antecedentes del romance de Nuño Vero, cita un pasaje de La chanson des Saisnes [...] muy relacionado con el tema de la prueba de Las señas del esposo: Badouin, amante de la reina Sebille, combate con Justamont (quien también está enamorado de la reina), lo mata y disfrazado con sus armas llega ante Sebille y la requiere de amores; el sobresalto de la reina hace que se identifique. Tenemos aquí todos los ingredientes de una parte de Las señas... disfraz, propuesta de amores, identificación final, y no falta tampoco la pregunta de ella: "Contez-nos vos noveles, trovaste Badouin?”. Quizás no sería muy arriesgado pensar que hubiera un romance que reprodujera este episodio entre Sebille y Badouin y que dicho romance hubiera tomado de las versiones de Gentilz gallans... las señas, la noticia de la muerte y la desolación, debido a coincidencias tales como la pregunta de ella, la muerte del amado (falsa en una y verídica en otra) y los lamentos de la mujer. [...] Dado que, según Menéndez Pidal, el romance de Nuño Vero tiene su antecedente en el pasaje del falso Justamont de La chanson des Saisnes (incluso con el "núcleo tradicional" de la pregunta: "contez-nos...": "preguntaros he por nuevas...”), el romance de Nuño Vero podría tener su origen en un primer texto 
más cercano al episodio francés y conservaría de este primer texto algunos versos. Este texto, antecesor de Nuño Vero, sería aquel que se unió a la versión española de Gentilz gallans de France y que también conservó los primeros versos, cambiando el nombre concreto de Valdovinos por el general de "esposo" ("amy” en Gentilz gallans...). (Díaz Roig 1979: 123-124)

Por tanto, para Mercedes Díaz Roig el origen del romance de Las señas del esposo sería una amalgama entre temas y motivos que aparecen en La chanson des Saisnes de Jean de Bodel y la canción Gentilz gallans de France. De la primera el romance habría tomado el motivo del subrepticio esposo que pone a prueba a su mujer y la identificación final de su personalidad; de la segunda, la preocupación de la esposa por el marido ausente, el motivo de las señas y la noticia de su muerte.

Como apuntan las hipótesis de Bronzini y Díaz Roig, probablemente existiera en la tradición oral medieval paneuropea un conjunto de temas y motivos, comunes al acervo folclórico del continente, que se intercambiarían entre sí con relativa frecuencia, dando lugar a fábulas e intrigas nuevas, y que viajarían fluidamente por las permeables fronteras lingüísticas y culturales de la Europa romance medieval ${ }^{21}$. Seguramente la raigambre de esos temas y motivos primigenios se remontaría todavía más lejos, a la tradición oral de la pan-Romania latina de la Alta Edad Media ${ }^{22}$, compartida por la mayor parte de Europa durante esos siglos en los que el latín fue la lengua franca de comunicación. E1 tamiz de los siglos convertiría el latín vulgar en las diversas lenguas románicas habladas por los habitantes del continente, quienes seguirían compartiendo un acervo folclórico de temas y motivos comunes, aunque ahora ya los cantaran en lenguas diferentes.

Pero independientemente de sus orígenes o sus posibles estemas, el romance de Las señas del esposo es el tema más difundido del romancero panhispánico, está presente en todas las subtradiciones y es, si no el primero como afirmaba Menéndez Pidal (1953: 360), uno de los que primero aparece en cualquier cala romancística. La razón para tamaña fortuna hay que buscarla en la funcionalidad como rasgo esencial y distintivo de la literatura tradicional, difundida oralmente durante siglos de generación en generación:

${ }^{21}$ Por ejemplo, Romeu i Figueras 1974: 230-232 defiende la existencia de una región comprendida entre el norte de Italia, sur de Francia y Cataluña que habría conocido desde antiguo un tipo de canción narrativa de rima asonante con un esquema métrico común y cuyo recuerdo habría permanecido en la tradición oral.

22 En el caso particular del tema de Las señas del esposo podría ser que tuviéramos que remontarnos a baladas griegas herederas directas de La odisea de Homero (Kioridis 2012: 67), si bien el tema es controvertido y especialistas como Ayensa Prat 2000: XII y 23-24 lo refutan defendiendo su génesis durante los siglos XIII y XIV en las islas del Égeo bajo el dominio franco. 
En la balada y el Romancero tradicional perviven únicamente aquellas narraciones que contienen un significado arquetípico, generalizable en forma de sucesos ejemplares, explicaciones de una realidad cultural y social, o incluso de sanciones y códigos de conducta. Para las comunidades de cantores que han transmitido determinadas narraciones y fábulas romancísticas, los romances no tienen la función de mantener viva la memoria del pasado, sino la de racionalizar su propio presente. (Cid Martínez, 2003: 162)

El tema de la fidelidad de la esposa, directamente asociado a la legitimidad de la descendencia, ha sido desde siempre una de las preocupaciones fundamentales de las sociedades patriarcales, como lo han sido las comunidades tradicionales campesinas donde se transmitían y recreaban oralmente los romances y en las que era relativamente frecuente la ausencia del marido para atender a los campos o al ganado, o para vender los productos de la cosecha o las reses, cuando no por alguna guerra en la que los varones (maridos o novios) voluntaria u obligatoriamente eran reclutados para servir en el ejército. Esta es seguramente la razón por la que el tema de Las señas del esposo se ha convertido en el romance más difundido de la tradición oral moderna. Existe además en Las señas del esposo otro motivo, presente en gran parte del corpus, que, a mi juicio, ha podido influir también de forma determinante en la fortuna del romance entre los transmisores tradicionales, reforzando aún más su funcionalidad para la comunidad de portadores. Si el tema de la fidelidad ejemplar de la esposa es básico en estas sociedades tradicionales campesinas, lo que bastaría sobradamente para explicar solo desde criterios de funcionalidad la extraordinaria difusión del tema en el folclore universal, no lo es menos el papel de los hijos - y sobre todo el de las hijas- en la estructura familiar de estas sociedades, donde tácitamente se reservaría a la hija más pequeña el deber de cuidar a los padres mayores, anulando sus posibilidades de poder formar a su vez una familia independiente. El romance actuaría como recordatorio de ese obligatorio e injusto papel que las hijas más jóvenes habrían de asumir, con fórmulas del tipo "y con la más chiquitica, / con esa me quedaré, // para que me lave y planche / y me busque de comer".

Como colofón de este trabajo reproduzco probablemente la más exótica de las versiones del corpus panhispánico del romance de Las señas del esposo, la cual, hasta donde tengo conocimiento, permanecía todavía inédita. Se trata de una versión de las Islas Filipinas. La envió en 1932 a Ramón Menéndez Pidal (1953: 359-360) el secretario de la Academia Filipina, Jaime C. de Veyra. Según Pidal, el mismo Veyra y un magistrado aficionado a la música serían los informantes de la versión, que recordarían desde la niñez. Sin embargo, en el original tipografiado conservado en el Archivo del Romancero Hispánico Menéndez Pidal/ Goyri, custodiado en la Fundación Ramón Menéndez Pidal (y cuya consulta me ha sido posible gracias a la generosidad de su presidente, Jesús Antonio Cid, que amablemente me la escaneó y envió por correo electrónico) el papel de Veyra 
como informante quedaría un tanto ambiguo, pues hay una anotación manuscrita donde se puede leer claramente:

Recitado en su niñez por D. Norberto Romuáldez, magistrado del Tribunal Supremo de Manila, y recordado por D. Jaime C. de Veyra, secretario de la Academia Filipina, 1932.

El texto de la versión es el siguiente:

- Oiga usté, señor soldado, ¿¿de qué tierra viene usted?

2 - Yo, señora, vengo de Asia, de la tierra de arabés.

¿Usté ha visto a mi marido en la guerra alguna vez?

4 - Sí señora, yo me acuerdo que se ha muerto ya hace un mes

y en su testamento dice que me case con usté.

6 - No permita el cielo santo ni la virgen Santa Inés.

Aquí tengo a mis tres hijas que tienen facciones de él.

8 La primera es blanca rubia tan blanca como el clavel;

la segunda es morenita, morena como la pez;

10 la tercera...............

En el verso 10 del original hay una nota que informa de que no fue posible al informante reconstruir el verso entero por olvido, pero no da información alguna sobre otros versos posteriores que así mismo se le hubiesen olvidado, por lo que la versión podría finalizar en este verso décimo. El texto posee un delicioso sabor local con la pintoresca variante "vengo de Asia", que creo única en el corpus del tema, o el nada frecuente símil "morena como la pez". Es una lástima que no se haya llevado a cabo una investigación de la tradición oral en Filipinas, pues esta versión apunta a sabrosas sorpresas que nos podrían haber deparado las versiones de romances de la tradición oral moderna filipina. 


\section{Bibliografía}

Acutis, Cesare (1974), "Romancero ambiguo", in Miscellanea di studi ispanici, I. Pisa: Università di Pisa.

Anahory-Librowicz, Oro (1989), "La sensualidad femenina en el romancero judeo-marroquí", in Literatura Hispánica, Reyes Católicos y descubrimiento: actas del Congreso Internacional sobre literatura hispánica en la época de los Reyes Católicos y el descubrimiento. Barcelona: PPU, 177-184.

Ayensa Prat, Eusebi (2000), Baladas griegas: estudio formal, temático y comparativo. Madrid: CSIC.

Bascom, W. R. (1965), "Four functions of folklore", in Alan Dundes (editor), The Study of Folklore. New Jersey: Prentice-Hall, 279-298.

Bénichou, Paul (1968), Romancero judeo-español de Marruecos. Madrid: Castalia.

Bonamore Graves, Alessandra (1986), Italo-Hispanic ballad relationships: the common poetic heritage. London: Tamesis.

Bronzini, Giovanni B. (1958), "Las señas del marido e La prova (con versioni inedite dell'Italia centro-meridionale)", Cultura Neolatina, vol. XVIII/ num. 2-3: 217-247.

Catalán, Diego (1997-1998), Arte poética del romancero oral, 2 vol. Madrid: Siglo XXI.

Catarella, Teresa (1990), "Feminine Historicizing in the romancero novelesco", Bulletin of Hispanic Studies, vol. LXVII/num. 4: 331-343.

Cid Martínez, Jesús Antonio (2003), "Romancero hispánico y balada vasca”, in Juan José Bustos Tovar (coordinador), Textualización y oralidad. Madrid: Instituto Universitario Menéndez Pidal-Visor libros, 157-188.

Devoto, Daniel (1959), “Entre las siete y las ocho”, Filología, Buenos Aires, vol. V/num. 1-2: 65-80.

Díaz Roig, Mercedes (1979), "Sobre una estructura narrativa minoritaria y sus consecuencias diacrónicas: el caso del romance de las señas del esposo", in Diego Catalán, Samuel G. Armistead y Antonio Sánchez Romeralo (editores), El romancero hoy: Poética. $2^{\circ}$ Coloquio Internacional sobre Romancero, University of California, Davis, Madrid, CSMP-University of California-Gredos, 121-131.

Ferré, Pere (2001), Romanceiro Português da Tradição oral moderna: versões publicadas entre 1828 e 1960, II. Lisboa: Fundação Calouste Gulbenkian.

Garrido de Boggs, Edna (1946), Versiones dominicanas de romances españoles. Ciudad Trujillo: Pol Hermanos.

Kioridis, Ioannis (2012), "El retorno del marido en el romancero y en las tragoúdia tradicionales griegas", Boletin de Literatura Oral, num. 2, 55-70. 
Martín Durán, Andrés Manuel (2016), El romancero tradicional en Cuba: historia de su recolección y versiones inéditas. Madrid: Fundación Universitaria Española.

Menéndez Pidal, Ramón (1953), Romancero hispánico (bispano-portugués, americano y sefardi). Teoría e Historia, 2 vol. Madrid: Espasa-Calpe.

Menéndez y Pelayo, Marcelino (1900), Antología de poetas líricos castellanos, tomo X. Madrid: Hernando y cia.

Milá y Fontanals, Manuel (1882), Romancerillo catalán. Canciones tradicionales, 2a ed. Barcelona: Álvaro Verdaguer.

Nigra, Constantino (1888), Canti popolari del Piamonte. Torino: Ermanno Loescher.

Paris, Gaston (1875), Chansons du XV siècle publiées d'après le manuscript de la Bibliothèque Nationale de Paris. Paris: Librairie de Firmon-Didot et cie.

Petersen, Suzanne H., Proyecto sobre el Romancero pan-hispánico, portal web [https://depts.washington.edu/hisprom/optional/balladaction. php?igrh=0113].

Propp, Vladimir (1971), Morfología del cuento. Madrid: Fundamentos.

Romeu i Figueras, Josep (1974), Poesía popular i literatura: estudios i textos. Barcelona: Curial.

Stefano, Giuseppe di (1973), El romancero. Madrid: Narcea. (1972), “Tradición antigua y tradición moderna. Apuntes sobre poética e historia del romancero", in Diego Catalán et al. (editores), El romancero en la tradición oral moderna. Primer Coloquio Internacional. Madrid: Seminario Menéndez Pidal-Gredos, 277-296.

Valenciano, Ana (1998), Os romances tradicionais de Galicia: catálogo exemplificado dos seus temas. Madrid/Santiago de Compostela: Fundación Ramón Menéndez Pidal/Xunta de Galicia.

Vicuña Cifuentes, Julio (1912), Romances populares y vulgares recogidos de la tradición popular chilena. Santiago de Chile: Imprenta Barcelona.

Wolf, Fernando José y Hofmann, Conrado (1856), Primavera y flor de romances o colección de los más viejos y más populares romances castellanos. Berlín: A. Asher y comp. 